\title{
Article
}

\section{Altered Psychological Responses to Different Magnitudes of Deception during Cycling}

Williams, Emily L., Massey, Hollie, SPARKS, S. ANDY, MIDGLEY, ADRIAN W., MARCHANT, DAVID C., BRIDGE, CRAIG A. and MCNAUGHTON, LARS R.

Available at https://clok.uclan.ac.uk/17044/

Williams, Emily L., Massey, Hollie orcid iconORCID: 0000-0002-9793-8702, SPARKS, S. ANDY, MIDGLEY, ADRIAN W., MARCHANT, DAVID C., BRIDGE, CRAIG A. and MCNAUGHTON, LARS R. (2015) Altered Psychological Responses to Different Magnitudes of Deception during Cycling. Medicine \& Science in Sports \& Exercise, 47 (11). pp. 2423-2430. ISSN 0195-9131

It is advisable to refer to the publisher's version if you intend to cite from the work. http://dx.doi.org/10.1249/MSS.0000000000000694

For more information about UCLan's research in this area go to

http://www.uclan.ac.uk/researchgroups/ and search for <name of research Group>.

For information about Research generally at UCLan please go to http://www.uclan.ac.uk/research/

All outputs in CLoK are protected by Intellectual Property Rights law, including Copyright law. Copyright, IPR and Moral Rights for the works on this site are retained by the individual authors and/or other copyright owners. Terms and conditions for use of this material are defined in the policies page. 
Title: Altered psychological responses to different magnitudes of deception during cycling

Running head: Magnitudes of deception in cycling time trials

Emily L. Williams ${ }^{1}$, Hollie S. Jones ${ }^{1}$, S. Andy Sparks ${ }^{1}$, Adrian W. Midgley ${ }^{1}$, David C. Marchant $^{1}$, Craig A. Bridge ${ }^{1}$ and Lars R. Mc Naughton ${ }^{1}$

1. Sports Performance Group

Edge Hill University, Department of Sport and Physical Activity

Send all correspondence to:

Professor Lars Mc Naughton

Edge Hill University,

St Helens Road,

Ormskirk,

Lancashire,

L39 4QP

lars.mcnaughton@edgehill.ac.uk

+441695657296 
Altered psychological responses to different magnitudes of deception during cycling

\section{CONFLICT OF INTEREST AND SOURCE OF FUNDING}

The authors have no conflicts of Interest

There are no sources of funding for this work

The results of the present study do not constitute endorsement by ACSM 


\section{Abstract}

2 Purpose: Deceptive manipulations of performance intensity have previously been investigated 3 in cycling time trials (TT), but used different magnitudes, methods and task durations. This

4 study examines previously employed magnitudes of deception, during $16.1 \mathrm{~km}$ TT and 5 explores as yet unexamined psychological responses. Methods: Fifteen trained cyclists 6 completed five TT, performing two alone (BLs), one against a simulated dynamic avatar 7 representing 102\% of fastest BL ( $\mathrm{TT}_{102 \%}$ ), one against a 105\% avatar ( $\mathrm{TT}_{105 \%)}$ ), and one against 8 both avatars (TT $102 \%, 105 \%)$. Results: Deceptive use of competitors to disguise intensity 9 manipulation enabled accomplishment of performance improvements greater than their 10 perceived maximal (1.3\% - 1.7\%). Despite a similar improvement in performance, during $\mathrm{TT}_{102 \%, 105 \%}$ 11 there was a significantly lower affect and self-efficacy to continue pace than $\operatorname{TT}_{105 \%}(\mathrm{p}<0.05)$, 12 significantly lower self-efficacy to compete than $\mathrm{TT}_{102 \%}(\mathrm{p}=0.004)$, and a greater RPE than $\mathrm{TT}_{\mathrm{FBL}}(\mathrm{p}$ $13<0.001)$. Conclusion: Since the interpretation of performance information and perceptions are 14 dependent on the manner in which it is presented; 'framing effect', it could be suggested that the 15 summative impact of two opponents could have evoked negative perceptions despite eliciting a similar 16 performance. Magnitudes of deception produce similar performance enhancement, yet elicit 17 diverse psychological responses mediated by the external competitive environment performing 18 in.

20 Key Words: Pacing Strategy, Power Output, Perceived Exertion, Affect, Self-efficacy 


\section{$21 \quad$ Introduction}

22 Teleoanticipatory setting of a pacing strategy for an athletic event is based upon expected task

23 demands (34). A confounding issue, however, is that the tactics, pacing strategies, and abilities 24 of opponents are relatively unknown, and somewhat surreptitious pre-competition. 25 Consequently, during a task, anticipatory pacing strategies require continual adjustment in an attempt to match goal-driven targets and in reaction to competitors' performances $(17,35,39)$.

27 Competition enforces decision making through the calculation of potential benefit and perceptions of risk, relating to a change in pace during the event (29). The associated actions and affective responses of these decisions then motivate behavioural choices and steer the amount of effort one is willing to exert $(35,42)$. Little is currently known about the decision making processes that influence pacing, or the underlying psychological mechanisms involved. This is despite evidence suggesting that the presence of competitors, who are striving to achieve the same outcome, interferes with athletes' psychological dispositions $(6,22,26,30)$. In particular, affect and goal achievement are pertinent to the selection of a pacing strategy (31). It is therefore important to gain further understanding of the effect of direct competition on these constructs, the physiological and psychological influences, and the resultant changes in behaviour and performance.

Visual simulated competitors have been employed in the laboratory setting to investigate the influence of direct competitor presence on cycling performance $(7,25,36,43,44)$. This

41 simulation of competitor behaviour improves the illusion of real-time feedback within a virtual environment (42) and enables instantaneous exploration of direct competition influences during performance (34). In addition, the provision of false information regarding an opponent's ability has manipulated task expectancy further examining the influence of competitor presence on performance outcomes $(7,43)$. Participants were informed they were 
competing against opponents of a similar ability to themselves, but in reality, were competing against their previous best performance. In contrast, Stone and colleagues deceived participants into believing that an on-screen avatar represented their fastest previous performance, but actually represented a performance corresponding to $2 \%$ greater power output (36). These manipulations of the expectant task demands and the use of simulated competitors resulted in observed behavioural changes and performance improvements, associated with changes in motivation (7,43), attentional focus (43), and pacing strategies (36). A false manipulation of feedback of 5\% greater speed than the previous best performance however has been shown to modulate pacing strategy, but had negligible impact on performance (24). The magnitude of the deception was seemingly too large to be maintained when attempted in a subsequent trial performed with accurate feedback as this would have been the equivalent to $14.5 \%$ power (13). In addition, Micklewright et al. did not include a competitor in their deception, where the additional influences associated with the presence of competition $(7,43)$ may have resulted in improved performances. Moreover, studies have manipulated previous performances using magnitudes of deception applied to a whole-trial average, i.e. $102 \%$ of average trial power output (36). This provides an unrealistic performance to compete against, or be used as a training tool, as a fixed pace for the task duration is both unrepresentative of the previous performance being simulated and a true competitor's behaviour. If they are to capture the temporal aspects of pacing decision making, researchers should consider using more sensitive manipulations that better replicate the dynamic pacing profile of the previous trial. Avatars can provide accurate visual representations of previously performed pacing variations, whilst concealing any deceptive manipulation applied to subsequent trials.

69 Research into the magnitude of deception that elicits performance improvements is in its 
71 performance have been performed using different methods (with and without competitive

72 simulations), different performance variables (power output and speed), and different distances

73 (4 km and $20 \mathrm{~km}$ ). This issue is notable since the effect of different magnitudes of deception

74 may be dependent on the duration of the task with respect to whether the deception remains

75 undetected, and whether successfully competing against the simulated competitor appears

76 achievable. Consequently, the different distances used by previous deception studies confound

77 the interpretation of findings with respect to the influence of magnitude of the deception on

78 performance outcomes. Further research into the influence of different magnitudes of deception

79 during the same distance events are therefore warranted, in which, adopting a distance that is

80 commonly performed during time trials would increase ecological validity.

81

82 The main aim of the present study was to investigate the effects of two magnitudes of deception

83 (102\% and 105\% speed manipulations), alone and simultaneously, on $16.1 \mathrm{~km}$ self-paced

84 cycling time trial (TT) performance. To address the limitations of existing research, this study

85 compares the two magnitudes across the same commonly performed distance and enhances

86 ecological validity employing a true competitor's pacing profile rather than an even pace

87 representation. Further inclusion of a novel condition allowed exploration into the influence of

88 the multiple competitor presence on performance. A secondary aim was to explore the

89 influence of psychological constructs, such as of affect and self-efficacy, on decision making

90 and performance outcomes.

91

92 Method

93 Participants

94 Twelve trained competitive male cyclists aged $35.2 \pm 5.0$ years; body mass $84.3 \pm 11.0 \mathrm{~kg}$;

95 height $179.4 \pm 6.5 \mathrm{~cm}$; and peak oxygen uptake (VंO2peak) $58.7 \pm 6.7 \mathrm{ml} \bullet \mathrm{kg} \bullet \mathrm{min}-1$ participated 
in this study. Each had over 8 yr competitive cycling experience, race experience in $16.1 \mathrm{~km}$

97 TTs and typical training volumes equating to $>8$ h.wk-1. VO2peak values obtained on the first visit categorised the participant’s performance level as ‘trained cyclists’ (9). The institutional ethics committee approved the study and all participants gave informed consent and completed health screening before participation. Prospective power analysis showed that a sample size of 12 participants achieves $86 \%$ power with a 5\% significance level and a minimum worthwhile effect of 2.2\% between conditions, equating to a standardised effect size of 1.1 (16).

\section{$104 \quad$ Experimental Design}

A repeated measures, counter-balanced design was implemented and participants visited the laboratory on six occasions performing a maximal oxygen uptake procedure and five $16.1 \mathrm{~km}$

TT. The trials were performed at the same time of day ( $\pm 2-h)$ to minimise circadian variation and were separated with 3-7 days to limit training adaptations. Participants were asked to maintain normal activity and sleep pattern throughout the testing period, and to replicate the same diet for the 24-h preceding each testing session. Participants refrained from any strenuous exercise, excessive caffeine, or alcohol consumption in the prior 24-h. They consumed $500 \mathrm{ml}$

112 of water and refrained from food consumption in the two hours before each visit. Hydration 113 state was assessed prior to trial commencement using a portable refractometry device 114 (Osmocheck, Vitech Scientific, West Sussex, UK). Participants were informed that the study was examining the influence of visual feedback during the TT, and were fully debriefed regarding the true nature of the study upon completion of all trial (19). All participation in the

117 study was kept anonymous, and in addition participants were asked to refrain from any 118 potential discussion with other participants until study completion. To prevent any pre119 meditated influence on preparation or pre-exercise state, the specific feedback presented was only revealed immediately before each trial. No verbal encouragement was given to the 
121 participants during any trial to prevent inconsistencies in the provision of this feedback.

122 Participants were instructed to complete each TT in the fastest time possible and to prepare for 123 each session as if it were a genuine competitive event.

124

125 Peak oxygen uptake

126 During their initial visit participants performed an incremental maximal exercise test on a cycle ergometer (Excalibur Sport Lode, Groningen, Netherlands), established as having co-efficient of variation of agreement with the Computrainer for both VंO2peak and heart rate as $8 \%$ and 4.4\% respectively (10). Following a 5-min warm-up at $100 \mathrm{~W}$, participants began the protocol at a prescribed resistance in accordance with accepted guidelines (British Cycling, 2003), and

$13120 \mathrm{~W}$ increments were applied until participants reached volitional exhaustion to determine 132 VंO2peak. Continuous respiratory gas analysis (Oxycon Pro, Jaeger, GmbH Hoechburg, 133 Germany) and heart rate (Polar Electro OY, Kempele, Finland) were measured throughout.

\section{$135 \underline{\text { Time trials }}$}

136 During five further visits, participants performed a $16.1 \mathrm{~km}$ cycling TT on their own bike, 137 mounted on a cycle ergometer (Computrainer Pro, Racermate ONE, Seattle, USA). This ergometer has previously reported to provide a reliable measure of power output (8) and produced a low coefficient of variation $(\mathrm{CV}=0.6 \%)$ for time, between two $16.1 \mathrm{~km}$ trials from

140 our laboratory. The ergometer was interfaced with the Computrainer's 3D visual software and 141 projected onto a $230 \mathrm{~cm}$ screen positioned $130 \mathrm{~cm}$ away from the cyclists front wheel and 142 calibrated according to manufacturer's instructions.

144 Prior to each TT participants completed a 10-min warm-up at $70 \%$ maximal heart rate 145 (HRmax), determined from the maximal test, followed by two minutes rest. The first TT 
146 familiarised participants with the equipment and procedures, during which participants

147 performed with a virtual visual display of an outdoor environment and total distance covered

148 throughout, as if performing on a flat, road-based $16.1 \mathrm{~km}$ course. Participants were not

149 informed that the initial visit was a familiarisation session, but that it was one of the four 150 experimental trials, to avoid a change in performance. The second visit replicated the

151 familiarisation trial and paired t-tests were performed to analyse the presence of any systematic

152 bias between the two baseline trials (BL). The two baseline trials showed no significant

153 differences in power output $(p=0.60)$, heart rate $(p=0.35), R P E(p=0.88)$, affect $(p=0.15)$

154 or self-efficacy ( $\mathrm{p}=0.58$ ). Only the faster of the two BL (TTFBL) was included in the inferential

155 analysis. Six participants performed their fastest baseline in their first baseline trial and the six

156 in their second baseline illustrating no evidence of a learning effect.

157

158 During three further visits participants were informed they would be competing against

159 simulated avatars projected on to the screen, and that the avatar's represented performances

160 produced by cyclists of a similar ability. Each competitive TT had different simulated avatars

161 as opponents, the order of which was randomised and counterbalanced. One was performed 162 with an avatar actually representing a performance $2 \%$ greater in speed than their fastest 163 baseline ( $\mathrm{TT}_{102} \%$ ), one representing a 5\% greater speed manipulation ( $\mathrm{TT}_{105 \%}$ ) and one 164 performed with simultaneous 2\% and 5\% avatars (TT102\%105\%). Distance covered and distance 165 of the lead avatar(s) were displayed throughout. Participants were blinded to all other data 166 (speed, power output, heart rate) during each experimental time trial.

168 Experimental measures

169 Power output, speed and elapsed time were blinded during all trials and stored at a rate of 34

170 Hz. Each were subsequently downloaded after performance for analysis. Percentage of mean 
171 speed across each quartile was also expressed to demonstrate pacing profiles. Heart rate was

172 also blinded and recorded continuously using polar team system sampled at 5-s frequencies.

173 These were then averaged as quartile data points for analysis. During each TT, breath-by-breath

174 respiratory gases were measured for the duration of a kilometre at every $4 \mathrm{~km}$, subsequently

175 averaged, and expressed in 5-s intervals. This intermittent collection of respiratory data was

176 adopted to allow for data collection whilst providing minimal interference on performance and

177 permit fluid intake $(500 \pm 20 \mathrm{ml})$ during the TT. Prior to each trial, willingness to invest

178 physical and mental effort were each assessed on a visual analogue scale ranging from 0 (not-

179 willing) to 10 (willing). Pre-task self-efficacy and affect were also recorded together with

180 measurements every $4 \mathrm{~km}$ during the trial. These pre-trial equivalence measures were

181 employed to determine consistency of pre-trial states across the conditions and identified no

182 significant differences between all trials across resting values of willingness to invest physical

183 effort $(p=0.11)$, willingness to invest mental effort $(p=0.75)$, hydration status $(p=0.17)$,

184 affect $(p=0.78)$ and self-efficacy $(p=0.73)$.

185

186 At each $4 \mathrm{~km}$ of the trial participants were asked to rate their perceived exertion (RPE) on a 6-

18720 scale Borg scale (3), and their affective feeling states as to whether the exercise felt pleasant

or unpleasant, measured using an 11-point Likert scale ranging from -5 to +5 with verbal anchors at all odd integers and zero $(+5=$ very good, $+3=$ good, $+1=$ fairly good, $0=$ neutral, -1 = fairly bad, -3 = bad, -5 = very bad). Additionally, at every 4 km self-efficacy to continue

191 at the current pace (SE $\mathrm{Sace}_{\text {), }}$ and their self-efficacy to compete with the competitor(s) for the 192 remaining distance of the trial during the competitor trials ( $\mathrm{SE}_{\text {comp }}$ ), was recorded on a 0-100\% scale divided into 5\% integer intervals. The self-efficacy scales were adopted from guidelines

194 previously developed and recently constructed (41). Post-trial interviews were completed and 195 qualitatively analysed using QSR NVivo 10 software (NVivo 10, QSR International Ltd, 
196 Cheshire, UK). Information was collected using semi-structured interviews pertaining to how 197 participants felt, their thoughts towards their pace, their thoughts towards the competitor, and what their strategy was during each $4 \mathrm{~km}$ of the trial. Data were collated into a thematic analysis followed by a process of descriptive frequencies.

200

$201 \quad \underline{\text { Statistical Analysis }}$

202 The effect of condition $\left(\mathrm{TT}_{\mathrm{FBL}}, \mathrm{TT}_{102 \%}, \mathrm{TT}_{105 \%}, \mathrm{TT}_{102 \%, 105 \%)}\right.$ and distance quartile (0-4 km, 4$2038 \mathrm{~km}, 8-12 \mathrm{~km}$ and 12-16.1 km), were analysed for completion time, power output, heart rate, 204 RPE, affect and self-efficacy variables using the mixed procedure for repeated measures (28). 205 Various plausible covariance structures were assumed for each dependant variable and the one 206 that minimised the Hurvich and Tsai's criterion (AICC) value was chosen as the best fitting 207 and used for the final model. A quadratic term for distance quartile was entered into the model 208 where appropriate and removed where no significance value was observed. Post hoc pairwise comparisons with Sidak-adjusted $\mathrm{p}$ values were conducted where a significant $\mathrm{F}$ ratio was

210 observed. In addition, bivariate relationships between pacing and psychological responses were 211 analysed using Pearson’s product moment correlations. Statistical significance was accepted as p $<0.05$ (IBM Statistics 22.0; SPSS Inc., Chicago, IL). Smallest worthwhile change in performance was calculated and expressed as a percentage change relative to TTFBL in addition,

214 to increase applicability and practically to athletes and coaches (18).

\section{$216 \underline{\text { Results }}$}

\section{Performance}

218 There was no significant main effect for condition $(\mathrm{F}=1.2, \mathrm{p}=0.34)$ observed for time trial 219 time (Table 1). The competitive trials were however performed faster than TTFBL; TT102\%105\% 220 (Mean difference, $\mathrm{MD}=-0.46 \mathrm{~min}, 95 \% \mathrm{CL}=-1.33,0.42 ; \mathrm{p}=0.61), \mathrm{TT}_{102} \%(\mathrm{MD}=-0.39 \mathrm{~min}$, 
95\% CL $=-1.05,0.27 ; \mathrm{p}=0.43)$ and $\mathrm{TT}_{105 \%}(\mathrm{MD}=-0.36 \mathrm{~min}, 95 \% \mathrm{CL}=-1.11,0.38 ; \mathrm{p}=$

222 0.67). Each of the competitor conditions elicited time trial time improvements greater than the 223 previously reported smallest worthwhile improvement, 0.6\% (28) and greater than the present 224 study's baseline trial coefficient of variation $(\mathrm{CV}=0.6 \%)$. $\mathrm{TT}_{102 \%}$ improved by $1.4 \%$, $\mathrm{TT}_{105 \%}$ 225 improved by $1.3 \%$ and $\mathrm{TT}_{102} \% 105 \%$ improved performance by $1.7 \%$. There was no significant 226 main effect for condition observed for speed $(\mathrm{F}=0.7, \mathrm{p}=0.58)$, however there was a significant 227 decrease in speed across distance quartile $(\mathrm{F}=7.6, \mathrm{p}=0.001)$. There was no significant condition $\mathrm{x}$ distance quartile interaction $(\mathrm{F}=0.054, \mathrm{p}=1.00)$, however during $\mathrm{TT}_{102 \%, 105 \%}$ participants did performance a greater starting strategy (Figure 1), of which a greater mean speed in the initial quarter of the trial was significantly correlated with a lower mean speed in the third quarter $(r=-0.848, \mathrm{p}<0.001)$,

\section{$\underline{\text { Physiological measurements }}$}

237 No significant main effects for condition $(\mathrm{F}=2.3, \mathrm{p}=0.11)$ or an interaction between condition and distance quartile $(\mathrm{F}=0.1, \mathrm{p}=0.99)$ were identified for heart rate. However, a main effect for distance quartile was observed with heart rate significantly increasing over time $(\mathrm{F}=24.5$, $\mathrm{p}<0.001)$. There was no main effect for condition for $\mathrm{VO} 2(\mathrm{~F}=1.1, \mathrm{p}=0.95)$, but a significant

241 main effect was evident for distance quartile $(\mathrm{F}=6.2, \mathrm{p}<0.001)$, with the final quartile 242 significantly higher than the second $(\mathrm{MD}=1.7 \mathrm{ml} . \mathrm{kg} \cdot \mathrm{min}-1,95 \% \mathrm{CL}=0.1,3.34 ; \mathrm{p}=0.04)$ and third quartile (MD = 2.0 ml.kg.min-1, 95\% CL = 0.7, 3.2; $\mathrm{p}<0.001$ ). There was however,

244 no condition $\mathrm{x}$ distance quartile interaction $(\mathrm{F}=0.2, \mathrm{p}=0.99)$. No significant condition effect 245 was observed for RER ( $F=1.3, p=0.27)$, but a main effect for distance quartile was seen ( $F$ 
$246=8.2, \mathrm{p}<0.001)$. The RER was significantly higher in the first quartile than in the second (MD

$247=0.03,95 \% \mathrm{CL}=0.01,0.05 ; \mathrm{p}=0.006)$ and the third $(\mathrm{MD}=0.04,95 \% \mathrm{CL}=0.02,0.06 ; \mathrm{p}<$

248 0.001). Additionally, the fourth quartile was significantly greater than the third $(\mathrm{MD}=0.03$, $24995 \% \mathrm{CL}=0.004,0.05 ; \mathrm{p}=0.013)$. There was no interaction $(\mathrm{F}=0.3, \mathrm{p}=0.97)$.

250

$251 \quad$ Psychological variables

252 Ratings of perceived exertion had a significant main effect for condition $(\mathrm{F}=13.4, \mathrm{p}<0.001)$, 253 in which RPE was significantly higher in TT102\% than FBL (MD = 0.8, 95\% CL = 0.3, 1.4; p $254<0.001)$ and $\mathrm{TT}_{102 \% 105 \%}$ significantly higher than in FBL $(\mathrm{MD}=0.9,95 \% \mathrm{CL}=0.4,1.3 ; \mathrm{p}<$ 255 0.001). The ratings of perceived exertion also significantly increased across distance quartiles $256(\mathrm{~F}=25.0, \mathrm{p}<0.001)$, but there was no condition $\mathrm{x}$ distance quartile interaction effect $(\mathrm{F}=0.4$, $257 \mathrm{p}=0.92$ ) (Figure 5.2a). There was a significant main effect for condition observed for affect $258(\mathrm{~F}=3.0, \mathrm{p}=0.03)$ with significantly higher values reported during $\mathrm{TT}_{105 \%}$ than during $259 \mathrm{TT}_{102 \% 105 \%}(\mathrm{MD}=-0.9,95 \% \mathrm{CL}=-1.8,-0.1 ; \mathrm{p}=0.03)$. Affect also significantly decreased 260 across distance quartiles $(\mathrm{F}=9.0, \mathrm{p}<0.001)$. There was no condition $\mathrm{x}$ distance quartile 261 interaction $(\mathrm{F}=0.2, \mathrm{p}=0.99)$ (Figure 5.2b). In addition during the first quartile of $\mathrm{TT}_{102 \% 105 \%}$ 262 significant positive correlations were observed between the percentage of mean speed 263 performed and RPE $(r=0.70, p=0.02)$ and a strong negative correlation with affect $(r=-0.6$, $264 \mathrm{p}=0.052)$.

265 There was a significant main effect for condition for $\mathrm{SE}_{\text {pace }}(\mathrm{F}=3.6, \mathrm{p}=0.03)$, but no 266 significant time effect $(\mathrm{F}=0.9, \mathrm{p}=0.45)$ or interaction $(\mathrm{F}=0.5, \mathrm{p}=0.87)$. Significantly greater $267 \mathrm{SE}_{\text {pace }}$ (Figure 5.2c) was found during $\mathrm{TT}_{105 \%}$ than during $\mathrm{TT}_{102 \%, 105 \%}(\mathrm{MD}=11.6 \%$, 95\% CL $268=-0.02,23.1 ; \mathrm{p}=0.05)$. There was a significant main effect across the three competitor trials 269 for $\mathrm{SE}_{\text {comp }}(\mathrm{F}=4.6, \mathrm{p}=0.02)$, however no significant main effect for distance quartile $(\mathrm{F}=2.7$, $270 \mathrm{p}=0.07)$ and no interaction $(\mathrm{F}=0.4, \mathrm{p}=0.91)$. Post hoc analysis found significantly higher 
$271 \mathrm{SE}_{\text {comp }}$ (Figure 5.2d) during $\mathrm{TT}_{102} \%$ when compared with $\mathrm{TT}_{105 \%}(\mathrm{MD}=15.8 \%, 95 \% \mathrm{CL}=5.3$,

272 26.3; $\mathrm{p}=0.001)$, and $\mathrm{TT}_{102 \%, 105 \%}(\mathrm{MD}=14.3 \% .95 \% \mathrm{CL}=3.7,24.8 ; \mathrm{p}=0.004)$.

273

274

[Insert Figure 2 near here]

275

276 Qualitative responses

277 Frequency data recorded from the post-trial questions found that the most common strategy

278 participants adopted during $\mathrm{TT}_{102 \%}$ was to 'stay ahead' of the competitor (41.7\%). During

$279 \mathrm{TT}_{105 \%}$ they adopted to 'go at own pace' (58.3\%), and during $\mathrm{TT}_{102 \%, 105 \%}$ they chose to 'ignore

280 the fastest competitor' (33.3\%). Participants' thoughts towards the competitor during TT $102 \%$

281 was to 'ignore' (25\%), as were the thoughts during TT105\% (50\%), as well as perceiving the 282 competitor to be 'too fast' (50\%). Whereas during TT $102 \% 105 \%$ thoughts were to 'concentrate on 283 the closer competitor' (41.7\%). The most frequent thoughts towards pace during TT102\% were 284 that it was 'manageable' (41.7\%), and during $\mathrm{TT}_{105 \%}$ and $\mathrm{TT}_{102 \%, 105 \%}$ that participant 'could 285 not sustain’ (50\% each).

287 Discussion

288 The primary aim of this study was to examine the influence of different magnitudes of 289 deception (102\%, 105\%) elicited through dynamic pacing avatars, on $16.1 \mathrm{~km}$ self-paced 290 cycling TT performance. This study is the first to investigate both of these magnitudes of 291 deception under the same task duration and further investigated such influences within a novel 292 competitive environment performing in the presence of two competitors. The main findings demonstrate that each method of deception, irrespective of its magnitude, elicited comparable 294 improvements in $16.1 \mathrm{~km}$ TT performance (1.3\% - 1.7\%) compared to performing alone. This 295 equates to a 'real-world' competitive advantage in the region of $21.6-27.0 \mathrm{~s}$ and highlights 
the ergogenic potential of increasing perceived maximal performances by deceptively altering performance feedback or stimulating a competitive environment. A secondary aim of our study was to explore the influence of different magnitudes of deception on psychological constructs during such performances. We demonstrate for the first time that although each magnitude of deception and competitive environment produced comparable performance improvements, they produced disparate psychological responses.

302

Performing against a single competitor, comparing different magnitudes of deceptively hidden performance intensity ( $\mathrm{TT}_{102} \%$ and $\mathrm{TT}_{105 \%}$ ), elicited similar improvements in performance times of $1.4 \%$ (23.4 s) and 1.3\% (21.6 s) respectively, compared to performing alone. These improvements are at least two times greater than the previously reported minimal worthwhile change in performance of $0.6 \%$ (representative of $10 \mathrm{~s}$ in the present study) (27). In support of previous research, despite different methodological approaches, the presence of simulated competitors improved TT performances greater than athletes’ previous best performance

310 (TT FBL $)(7,36,43)$. This includes improvements when misleading feedback is presented as a competitor representing a performance $2 \%$ greater than the athlete’s previous best performance (36). Whilst the present study supports such findings it must be noted that the $2 \%$ increase in power output manipulation in the previous study will represent a $0.7 \%$ increase in speed during

314 comparisons to the present investigation (13).

316 Important to note however, is that whilst the findings of facilitation even when against a 2\% 317 increase in performance correspond with previous research, the present study informed the 318 participants differently as to the nature of their competitor. During the present study 319 participants were informed their visual opponent was a cyclist of a similar ability to themselves. 320 In contrast, during Stone et al's (2012) research, participants were informed the avatar 
321 represented their own previous performance. Caution must be sough when directly comparing

322 such results as performing against self or an opponent will alter the intrinsic and extrinsic nature

323 of competitive motivation and could influence the behavioural strategy one chooses during

324 competition (40). Nevertheless, the present methodology enabled a true comparison of

325 manipulation magnitudes between $100 \%, 102 \%$ and $105 \%$ of the same performance variable,

326 and a novel finding is that performance also improved when misleading feedback is presented

327 as a competitor representing a performance 5\% greater in speed than the athlete's previous best

328 performance.

329

330 Simultaneous with similar improvements in performance times across the conditions, there

331 were also no significant differences in the physiological or psychological responses between

$332 \mathrm{TT}_{102 \%}$ and $\mathrm{TT}_{105 \%}$. There was no significant difference between trials for RPE, affect, and

333 athlete's self-efficacy to continue at the chosen pace. Participants did however report a

334 significantly greater during-task self-efficacy to compete with their opponent during $\mathrm{TT}_{102 \%}$

335 compared to $\mathrm{TT}_{105 \%}$ and interestingly, both trials resulted in more positive affect than $\mathrm{TT}_{\mathrm{FBL}}$

336 despite an increase in exercise intensity. The findings during $\mathrm{TT}_{102} \%$ support the proposal that

337 greater affective valence is observed despite an increase in pace, if the subject successfully

338 stays in contact with a competitor (29). Alternatively it has previously been proposed that

339 athletes who realise that they are failing to achieve meaningful goals during competition,

340 represented in the present study as lower self-efficacy to compete with the simulated

341 competitor, experience a negative affective state labelled 'competitive suffering' $(5,12)$. If the

342 subject cannot stay in contact with the competitor, a reduced affect and increased RPE might

343 be expected. This however, was not evident during $\mathrm{TT}_{105 \%}$, despite participants indicating an

344 inability to stay with their opponent through their reduced self-efficacy responses, and post-

345 trial interviews, in which half the participants expressed they could not sustain the pace. There 
was a significantly lower self-efficacy to compete during $\mathrm{TT}_{105 \%}$ than during $\mathrm{TT}_{102 \%}$, yet they expressed similar affect to $\mathrm{TT}_{102 \%}$, which was more positive than during $\mathrm{TT}_{\mathrm{FBL}}$. Notably, during post-trial feedback half the participants reported that they abandoned competing with the avatar and continued to ride the trial for time, rather than as a competition, during $\mathrm{TT}_{105 \%}$. This supports that people with low task- or self-efficacy may avoid such goal attempts (33), and that if an athlete is not in close proximity to their competitors, pacing is better focused on producing an optimal individual performance (32). However the temporal aspects of such decision making require further consideration. Whilst the two magnitudes of deceptive manipulations produced similar improvements in performance time when competed against as a single competitor, their differential influence on perceptions of self-efficacy is noteworthy.

The summative effect of competing against two avatars during the same trial has not previously been investigated. Whilst the presence of competitors during each condition ( $\mathrm{TT}_{102 \%}$, $\mathrm{TT}_{105 \%}$ and $\mathrm{TT}_{102 \%, 105 \%)}$ elicited similar improvements in performance time $(1.4 \%, 1.3 \%$ and $1.7 \%$

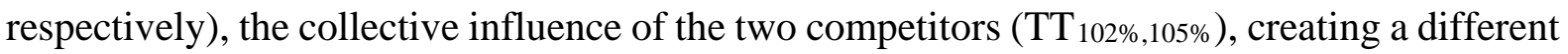
competitive environment (albeit representative of the same pacing profiles experienced within the single competitor conditions), produced different psychological responses. A significantly greater RPE was observed during $\mathrm{TT}_{102} \% 105 \%$ and $\mathrm{TT}_{102} \%$ than during TTFBL. However RPE during $\mathrm{TT}_{105 \%}$ was not significantly greater than TTFBL. The contrasting responses could be explained by the decision in $\mathrm{TT}_{105 \%}$ to change the performance goal away from competing with the avatar, as expressed by participant's post-trial. Thus the perceptions of exertion are significantly increased when competing with opponents, compared to striving to reach personal goals, such as during alone conditions and $\mathrm{TT}_{105 \%}$ (30). Notably, research has recently documented performance improvements in the absence of elevated RPE when competing with an avatar, which was ascribed to the greater external attentional focus during the task (43). 
371 However, this former study employed an avatar representing 100\% of previous performance,

372 whereas the present study used greater intensity magnitudes of $102 \%$ and $105 \%$. Such

373 increased work-rate may negate any processing of external information through greater

374 salience of physiological feedback. As such, competing against opponents who are superior to

375 an athlete’s previous fastest performance elevates RPE (36).

376

377 There was also significantly lower affect during $\mathrm{TT}_{102} \%, 105 \%$ than $\mathrm{TT}_{105 \%}$. Competing against

378 two opponents evoked meaningful performance improvements despite participants

379 experiencing higher RPE and lower affect. An explanation for the more negative affective

380 responses and heightened perceived exertion during $\mathrm{TT}_{102 \%, 105 \%}$ could be the 'framing effect'

381 of the feedback provided (29). Emotional responses and the interpretation of afferent physiological sensations are dependent on the circumstances in which information is presented to the individual $(23,30)$. Therefore performing against two competitors could have been perceived as more stressful than against a single competitor or performing alone, encouraging more negative perceptions. Additionally, affective and psychological responses could have been influenced by self-efficacy appraisals. There is a proposition that variations in selfefficacy are antecedents of variability in affective responses (11) and that sensations of fatigue are interpreted differently according to one’s degree of self-efficacy (21). During TT102\%105\% participants reported significantly lower self-efficacy to compete than during TT102\%. One’s perceived progress towards goal achievement is important in the generation of affect responses

391 (14). Therefore the lower self-efficacy during $\mathrm{TT}_{102 \% 105 \% \text {, possibly generated according to a }}$ perceived greater risk towards the achievement of their overall goal when competing against two opponents, may have resulted in reduced affective valence. The self-efficacy question was

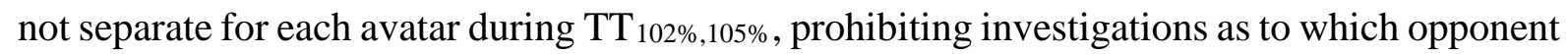
they were anchoring their appraisal of self-efficacy. The values were, however, similar to those 
reported during $\mathrm{TT}_{105 \%}$, and both ( $\mathrm{TT}_{105 \%}$ and $\mathrm{TT}_{102 \%, 105 \%}$ ) had significantly lower self-

397 efficacy than $\mathrm{TT}_{102 \%}$. Additionally it could be assumed that during $\mathrm{TT}_{102 \%, 105 \%}$ the influence of the $102 \%$ avatar, in closer proximity, motivated the choice to continue competing despite worse affective and efficacy responses. This as $41.7 \%$ of the participant's specified that they 400 chose to concentrate on the closer competitor. As previous findings have elucidated (38), 401 similar deception methods allow for the association of negative affect with successful 402 performances through an enhanced motivation to withstand a workload otherwise considered unsustainable.

404

405 A further explanation for the similar improvement in performance despite worse affective and

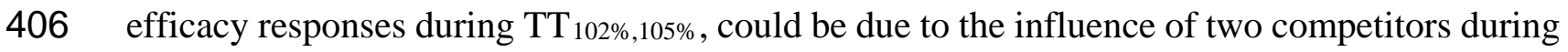
407 the initial $4 \mathrm{~km}$. Whilst the cyclists' speed profiles across all trials was illustrative of the 408 commonly reported parabolic pacing strategy (1), during $\mathrm{TT}_{102 \%, 105 \%}$ there was a greater percentage of mean speed displayed in the initial quarter of the trial (Figure 1). This suggests

410 participants did not select their initial pace from their perceived optimal strategy, but adjusted 411 their speed to that imposed by the competition (39). Extending the findings of previous research, individuals are likely to select work rates based on the behaviour of competitors and be less influenced by afferent information relating to their personal status (29). In which, during

$414 \mathrm{TT}_{102 \%, 105 \%}$ a faster start was found to be significantly associated with greater RPE and a 415 reduced affect. The presence of competition, in particular two competitors, may have induced 416 greater motivation (2), encouraging acceptance of a high level of unpleasant sensations in an 417 attempt to achieve a goal of beating the opponents.

419 The selection of an unsustainable power output at the start of $\mathrm{TT} 102 \%, 105 \%$ possibly led to the 420 necessity to slow down during the third quarter (15). Consciously reducing power output during 
421 the third quarter (37), in response to a greater initial $4 \mathrm{~km}$ pace, is further evidence supporting

422 a psychophysiological pacing decision as an active step to maintain overall pacing strategy and

423 preventing a physiological catastrophe (39). This was also demonstrated in previous research

424 using a 105\% speed manipulation (24). Furthermore, the pacing profile for $\mathrm{TT}_{102 \%, 105 \%}$

425 illustrated that athletes were still able to increase pace in the final quartile, which is indicative

426 of the presence of a reserve. The motivational influence of competition $(7,43)$, could be

427 considered an incentive that in spite of unpleasant experiences (increased RPE and reduced

428 affect) during TT 102\%,TT105\% performance was not debilitated. This provides further support for

429 previous findings of a significant negative association between affect and power output during

$43016.1 \mathrm{~km}$ time trials (20), and between affect and increased task performance (38).

431

432 Conclusion

433 In conclusion, data from the current study confirms the beneficial effect of the surreptitiously 434 augmented feedback of a previous performance. Deceptive employment of dynamic 435 competitors to disguise the intensity manipulation enabled cyclists to accomplish performance 436 improvements, even with a magnitude increase of $2 \%$ and $5 \%$ greater speed than previous 437 performance. Although supporting previous findings that deception magnitudes of 105\% speed were too large to be sustained for the whole task, when this magnitude is presented as direct competition, participants may change their performance goal to prevent a reduced performance 440 and negative emotions. Notably, participant's willingness to achieve their competitive goal 441 when against two opponents, increased persistence of performance by counteracting negative 442 psychological responses of greater RPE, and permitted the acceptance of reduced affect.

443 Finally, the magnitude to which the feedback is augmented and the way in which it is presented 444 to athletes stimulates different psychological influences. When implementing this strategy into 445 practice or training, consideration must therefore be given to the implications associated with 
446 different magnitudes of deception and the use of competitive environments upon previously 447 unexamined psychological constructs. 


\section{$\underline{\text { References }}$}

1. Abbiss, CR, Laursen, PB. Describing and understanding pacing strategies during athletic competition. Sports Med. 2008; 38(3): 239-252.

2. Baron B, Moullan F, Deruelle F, Noakes TD. The role of emotions on pacing strategies and performance in middle and long duration sport events. Br J Sports Med. 2009; 45(6): 511-7.

3. Borg G. Perceived exertion as an indicator of somatic stress. Scand J Rehabil Med. 1970; 2(2): 92-8.

4. British Cycling. Test Methods Manual. British Cycling Website. Manchester (UK): British Cycling; [cited 2003 Sept 22]. Available from: http://www.britishcycling.org.uk.

5. Bueno J, Weinberg RS, Fernandez-Castro J, Capdevila L. Emotional and motivational mechanisms mediating the influence of goal setting on endurance athletes' performance. Psychol Sport Exerc. 2008; 9(6): 786-799.

6. Cohen J, Reiner B, Foster C et al. Breaking away: effects of nonuniform pacing on power output and growth of rating of perceived exertion. Int J Sports Physiol Perf. 2013; 8(4): 352-7.

7. Corbett J, Barwood MJ, Ouzounoglou A, Thelwell R, Dicks M. Influence of competition on performance and pacing during cycling exercise. Med Sci Sports Exerc. 2012; 44(3): 509-15.

8. Davison RR, Corbett J, Ansley L. Influence of temperature and protocol on the calibration of the Computrainer electromagnetically-braked cycling ergometer: original research article. Int Sport Med J. 2009; 10(2): 66-76.

9. De Pauw K, Roelands B, Cheung SS, De Geus B, Rietjens G, Meeusen R. Guidelines to classify subject groups in sport-science research. Int J Sports Physiol Perf. 2013; 8(2): 111-122.

10. Earnest CP, Wharton RP, Church TS, Lucia A. Reliability of the Lode Excalibur Sport Ergometer and applicability to Computrainer electromagnetically braked cycling training device. J Strength Cond Res. 2005; 19(2): 344-348.

11. Ekkekakis P, Hall EE, Petruzzello SJ. Variation and homogeneity in affective responses to physical activity of varying intensities: an alternative perspective on dose-response based on evolutionary considerations. J Sports Sci. 2005; 23: 477-500 
12. Evans MB, Hoar SD, Gebotys RJ, Marchesin Ca. Endurance athletes’ coping function use during competitive suffering episodes. Eur J Sport Sci. 2013; 14(4): 368-375

13. Flyger N. Variability in competitive performance of elite track cyclists. ISN Bull. 2008;1:27-32.

14. Gaudreau P, Blondin JP, Lapierre AM. Athletes' coping during a competition: relationship of coping strategies with positive affect, negative affect, and performancegoal discrepancy. Psychol Sport Exerc. 2002; 3(2): 125-150.

15. Hall EE, Ekkekakis P, Petruzzello SJ. Is the relationship of RPE to psychological factors intensity-dependent? Med Sci Sports Exerc. 2005; 37(8): 1365-1373.

16. Hintze J. (2011). PASS 11. NCSS, LLC. Kaysville, Utah, USA. Available from: www.ncss.com. (accessed on: $28^{\text {th }}$ October 2013)

17. Hockey GR. Compensatory control in the regulation of human performance under stress and high workload; a cognitive-energetical framework. Biological psychol. 1997; 45(1-3), 73-93.

18. Hopkins WG, Hawley JA, Burke LM. Design and analysis of research on sport performance enhancement. Med Sci Sports Exerc. 1999; 31(3): 472-485.

19. Jones HS, Williams EL, Bridge CA et al. Physiological and psychological effects of deception on pacing strategy and performance: A review. Sports Med. 2013; 43(12):1243-57

20. Jones HS, Williams EL, Marchant D et al. Distance-dependent association of affect with pacing strategy in cycling time trials. Med Sci Sports and Exerc. 2014; doi:10.1249/MSS.0000000000000475 [ahead of print]

21. Knicker AJ, Renshaw I, Oldham ARH, Cairns SP. Interactive processes link the multiple symptoms of fatigue in sport competition. Sports Med. 2011; 41(4): 307-28.

22. Le Meur Y, Dorel S, Baup Y, Guyomarch JP, Roudaut C, Hausswirth C. Physiological demand and pacing strategy during the new combined event in elite pentathletes. Eur $J$ App Physiol. 2012; 112(7): 2583-93.

23. Martino B, De Kumaran D, Seymour B, Dolan RJ. Frames, Biases, and Rational Decision-Making in the Human Brain, Sci. 2006; 313 (5787): 684-687.

24. Micklewright D, Papadopoulou E, Swart J, Noakes T. Previous experience influences pacing during 20 km time trial cycling. Br J Sports Med. 2010; 44(13): 952-60.

25. Noreen EE, Yamamoto K, Clair K. The reliability of a simulated uphill time trial using the Velotron electronic bicycle ergometer. Eur J App Physiol. 2010; 110(3): 499-506. 
26. Pageaux B. The psychobiological model of endurance performance : An effort-based decision-making theory to explain self-paced endurance performance, Sports Med. 2014; 44(9):1319-1320.

27. Paton CD, Hopkins WG. Variation in performance of elite cyclists from race to race. Eur J Sport Sci. 2006; 6(1): 25-31.

28. Peugh JL. Using the SPSS Mixed procedure to fit cross-sectional and longitudinal multilevel models. Educ Psychol Measur. 2005; 65(5): 717-741.

29. Renfree A, Martin L, Micklewright D, St Clair Gibson A. Application of decisionmaking theory to the regulation of muscular work rate during self-paced competitive endurance activity. Sports Med. 2014; 44(2): 147-58.

30. Renfree A, St Clair Gibson A. Influence of different performance levels on Pacing strategy during the female world championship marathon race. Int $J$ Sports Physiol Perf. 2013; 8(3): 279-285.

31. Renfree A, West J, Corbett M, Rhoden C, St Clair Gibson A. Complex interplay between determinants of pacing and performance during $20 \mathrm{~km}$ cycle time trials. Int $J$ Sports Physiol Perf. 2012; 7(2): 121-129.

32. Roelands B, De Koning J, Foster C, Hettinga F, Meeusen R. Neurophysiological determinants of theoretical concepts and mechanisms involved in pacing. Sports Med. 2013; 43(5): 301-11.

33. Schunk DH. Self-efficacy and achievement behaviors. Educ Psychol Rev, 1989; 1: 17320

34. Smits BLM, Pepping GJ, Hettinga FJ. Pacing and decision making in sport and exercise: the roles of perception and action in the regulation of exercise intensity. Sports Med. 2014; 4(6): 763-75.

35. St Clair Gibson A, De Koning JJ, Thompson KG et al. Crawling to the finish line: why do endurance runners collapse? Implications for understanding of mechanisms underlying pacing and fatigue. Sports Med. 2013; 43(6): 413-24.

36. Stone MR, Thomas K, Wilkinson M, Jones AM, St Clair Gibson A, Thompson KG. Effects of deception on exercise performance: implications for determinants of fatigue in humans. Med Sci Sports Exerc. 2012; 44(3): 534-41.

37. Swart J, Lamberts RP, Lambert M I et al. Exercising with reserve: exercise regulation by perceived exertion in relation to duration of exercise and knowledge of endpoint. $\mathrm{Br}$ J Sports Med. 2009; 43(10): 775-81. 
38. Taylor D, Smith MF. Effects of deceptive running speed on physiology, perceptual responses, and performance during sprint-distance triathlon. Physiol Behav. 2014; $133: 45-52$

39. Thiel C, Foster C, Banzer W, De Koning J. Pacing in Olympic track races: competitive tactics versus best performance strategy. J Sports Sci. 2012; 30(11): 1107-15.

40. Uziel L. Individual differences in the social facilitation effect: A review and metaanalysis. J Res in Pers. 2007; 41(3): 579-601.

41. Welch AS, Hulley A, Beauchamp M. Affect and self-efficacy responses during moderate-intensity exercise among low-active women: the effect of cognitive appraisal. J Sport Exerc Psychol. 2010; 32(2): 154-175

42. Wellner M, Sigrist R, Riener R. Virtual competitors influence rowers. PRESENCE: Teleoperators and Virtual Environments. 2010; 19(4): 313-330.

43. Williams EL, Jones HS, Andy Sparks S, Marchant DC, Midgley AW, Mc Naughton LR. Competitor presence reduces internal attentional focus and improves $16.1 \mathrm{~km}$ cycling time trial performance. J Sci Med Sport. 2014; 3-8 doi:10.1016/j.jsams.2014.07.003.

44. Zavorsky GS, Murias JM, Gow J et al. Laboratory 20-km cycle time trial reproducibility. Int J Sports Med. 2007; 28(9): 743-8. 
Table 1. Mean \pm SD completion time and whole TT average power output, speed, and heart rate for the three experimental conditions.

\begin{tabular}{|c|c|c|c|c|}
\hline Condition & Completion Time (min) & Power Output (W) & Speed $(\mathrm{km} / \mathrm{h})$ & Heart Rate (bpm) \\
\hline $\mathrm{TT}_{\mathrm{FBL}}$ & $27.2(2.1)$ & 252 (45) & $35.8 \quad(2.6)$ & 159 (14) \\
\hline $\mathrm{TT}_{102 \%}$ & 26.8 (1.6) & 259 (38) & $36.2(2.0)$ & $162(11)$ \\
\hline $\mathrm{TT}_{105 \%}$ & 26.8 (1.6) & 258 & $36.2(2.8)$ & 159 (11) \\
\hline $\mathrm{TT}_{102 \%, 105 \%}$ & 26.7 (1.9) & 260 (44) & $36.3(2.4)$ & $159 \quad(12)$ \\
\hline
\end{tabular}
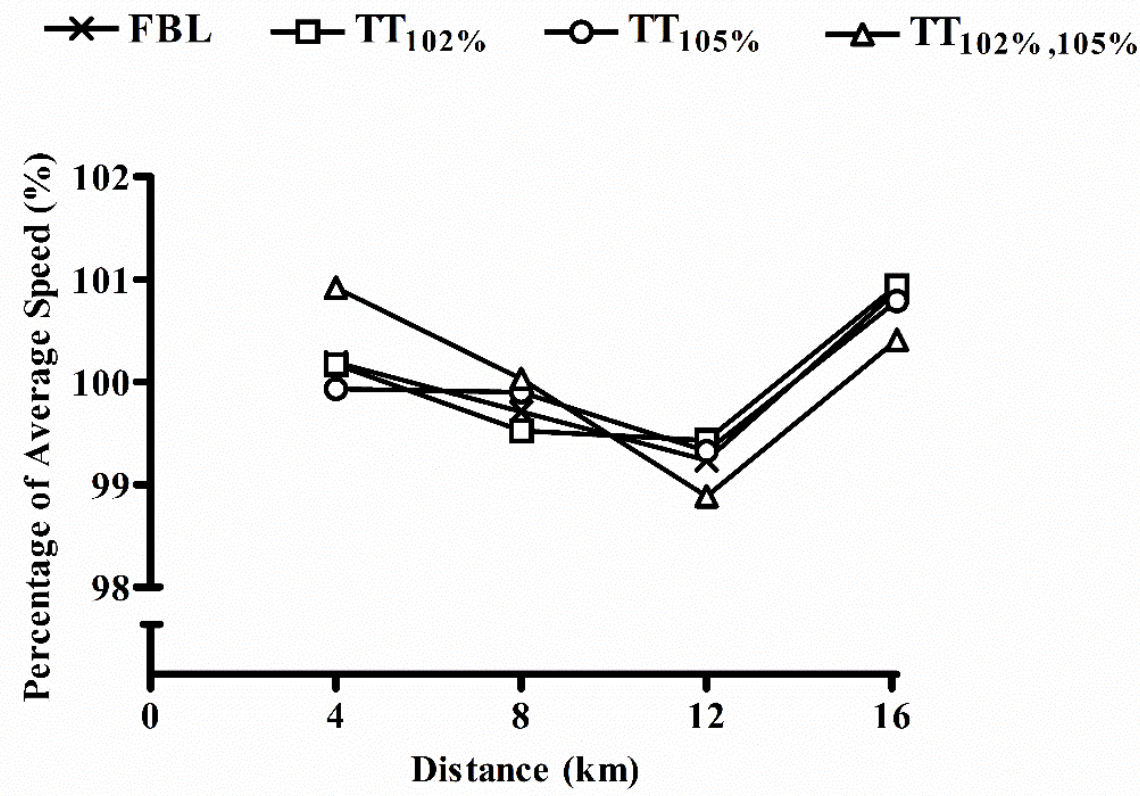

Figure 1. Percentage of mean speed during each time trial. Error bars are omitted for clarity. 


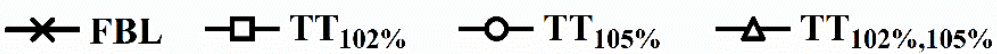

a

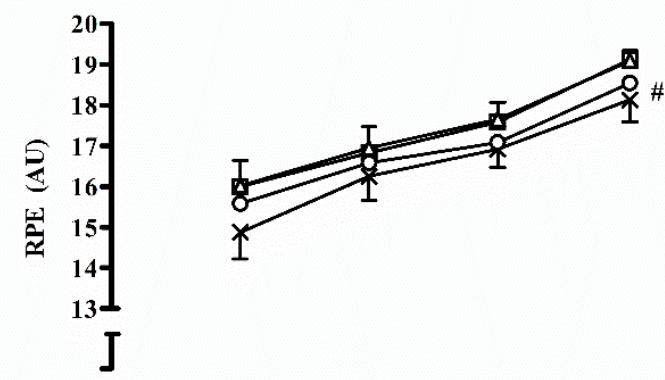

c

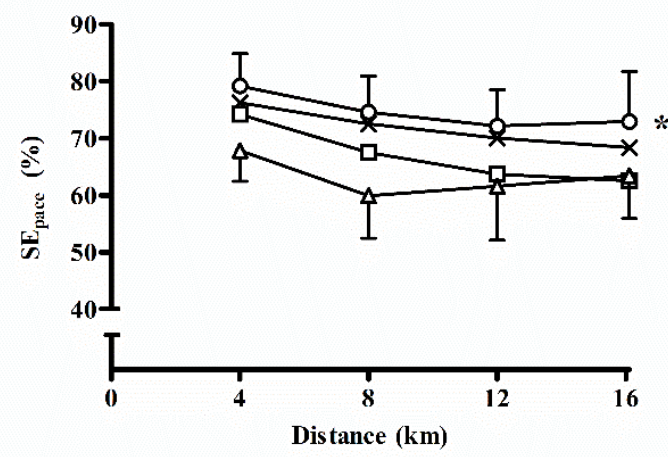

b

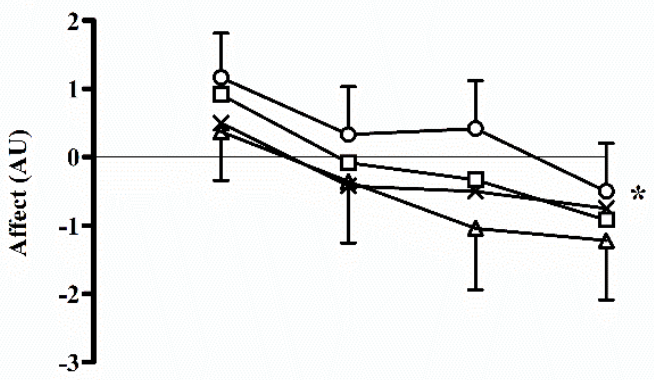

d

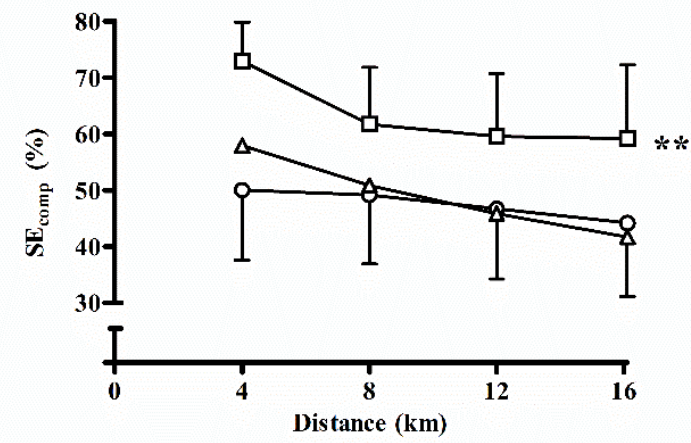

Figure 2. Psychological responses to the TT conditions. a) Ratings of perceived exertion, b) Affect, c) $S E_{\text {pace, d) }} \mathrm{SE}$ comp. Error bars illustrate SEM. (\#) Denotes main effect for condition, TTFBL significantly different to $\mathrm{TT}_{102} \%(\mathrm{p}<0.001)$ and $\mathrm{TT}_{102 \% 105 \%}(\mathrm{p}<0.001)$. $\left(^{*}\right)$ denotes main effect for condition, $\mathrm{TT}_{105 \%}$ significantly different to $\mathrm{TT}_{102 \% 105 \%}(\mathrm{p} \leq 0.05)$. $\left({ }^{* *}\right)$ denotes main effect for condition, $\mathrm{TT}_{102} \%$ significantly different to $\mathrm{TT}_{105 \%}(\mathrm{p}=0.001)$ and $\mathrm{TT}_{102 \%, 105 \%}(\mathrm{p}=0.004)$. 